\title{
Evaluation of Self-reported Insomnia and Its Association with Some Geriatric Syndromes in Older Adults
}

\author{
(D) Banu Özulu Türkmen \\ Istanbul University Istanbul Faculty of Medicine, Department of Geriatrics, Istanbul, Turkey
}

\begin{abstract}
Objective: Sleep is a reversible state of altered consciousness, characterized by decreased response to environmental stimuli. The American Academy of Sleep Medicine Guideline 2017 defined insomnia as the subjective perception of problems with initiation, duration and quality of sleep leading to daytime impairment. Sleep problems are common among adults over the age of 65, with a reported prevalence of 50-70\%. In the older population, sleep disorders have been associated with poor quality of health, falls, inappropriate medication use and higher rates of morbidity and mortality. In our study, we aimed to evaluate the frequency of sleep problems and their relationship with some geriatric syndromes.
\end{abstract}

Materials and Methods: Medical reports of patients who presented to our outpatient clinic between November 2013 and November 2016 were retrospectively analysed and the association of sleep problems with age, gender, falls, frailty, and restless leg syndrome (RLS) was evaluated.

Results: A total of 295 geriatric patients were included in the study. Sixty-six percent of the patients $(n=196)$ were female and 34\% $(n=99)$ were male. The mean age was $75.6 \pm 6.8$ years. The prevalence of sleep problems was $47.8 \%$. Bivariate analysis showed that insomnia was significantly related with age, polypharmacy and RLS. There was no statistically significant difference between genders. In regression analysis, age, polypharmacy and RLS were independently associated with insomnia.

Conclusion: Sleep disorders in the older adults is a major health problem affecting the quality of life and should be questioned during outpatient clinic visits. It should be kept in mind that sleep problems may be related to important geriatric syndromes.

Keywords: Insomnia, older population, restless leg syndrome

\section{Introduction}

Sleep is a reversible state of altered consciousness, characterized by decreased response to environmental factors and stereotypical electroencephalography changes $(1,2)$. Age-associated changes in sleep and circadian rhythm start in early as in forties and increase with age (3). Older people tend to have a disrupted sleep efficiency, and frequency of sleep disorders raises with aging (4). Insomnia disorder is defined as the subjective report of the problems with falling asleep, duration and quality that cause daytime impairment. Insomnia is identified as chronic, if it persists for at least three months three times per a week (5). The prevalence of short-term insomnia is reported 30\%-50\% in adults and chronic insomnia is reported as at least $5-10 \%$ in industrialized countries (5-7). The prevalence of insomnia in older population varies between 18\%-65\% (8-11). Restless leg syndrome (RLS) is the unpleasant feeling (numbness, ache, tingling) in the legs that cause urge to move, especially in the evening. It is also related with insomnia and sleep disruption and reported more prevalent in older adults $(8,12)$. RLS is reported as a common cause of insomnia; as much as $85 \%$ of patients with RLS were reported to have insomnia (13).

Sleep is essential and important in every stage of life. Sleep disorders were found to be related with many undesirable health outcomes significant for the older adults such as cognitive problems, depression, fatigue, falls, metabolic syndrome, cardiovascular problems, polypharmacy and inappropriate medication use (14-18)

Address for Correspondence: Banu Özulu Türkmen MD, İstanbul University İstanbul Faculty of Medicine, Department of Geriatrics, İstanbul, Turkey Phone: +90 5330297822 E-mail: dr_banu84@hotmail.com ORCID: orcid.org/0000-0003-3492-874X

Received: Feb 22, 2019 Accepted: Apr 17, 2019

This article was presented in $11^{\text {th }}$ Academic Geriatric Congress and 14 th the Eugms Congress as an oral presentation in 2018.

Cite this article as: Türkmen Özulu B. Evaluation of Self-reported Insomnia and Its Association with Some Geriatric Syndromes in Older Adults. Eur J Geriatr Gerontol 2019;1(1):11-16

${ }^{\circ}$ Copyright 2019 by the Academic Geriatrics Society / European Journal of Geriatrics and Gerontology published by Galenos Publishing House. 
A few published studies evaluated the prevalence of insomnia and RLS among older adults in Eastern Europe. On the other hand, the number of the studies investigating the relation between sleep disorders and polypharmacy and inappropriate medication use is limited. In this study, we aimed to evaluate the prevalence of insomnia and RLS among older patients admitted to our outpatient clinic in Turkey and examine the relation between insomnia/RLS and demographic data (gender and age), frailty, falls and polypharmacy.

\section{Materials and Methods}

The medical records of patients, aged $\geq 60$ years admitted to geriatric outpatient clinic at İstanbul University İstanbul Faculty of Medicine between November 2013-November 2016 were evaluated retrospectively. Patients who were questioned for insomnia, RLS and falls were included. Exclusion criteria were age $<60$ years, any missing data on sleep, RLS or falls.

Gender, age, presence of insomnia, restless leg symptoms, history of falls, presence of polypharmacy and frailty status were noted from the patient files.

Insomnia was assessed by asking the patients if they experienced difficulty in falling sleep and/or maintaining sleep (19). For evaluating RLS a single question was asked; do you experience unpleasant and restless feeling in your legs which is relieved by walking or movement (20). Patients were asked if they had experienced any fall during the last year. Polypharmacy was defined as the use of $\geq 4$ medications (21). Frailty was assessed by FRAIL scale which includes five components; fatigue, resistance, ambulation, illness and loss of weight. Frail scale scores range $0-5 ; \geq 3$ represents frail, 1-2 pre-frail and 0 for robust health status (22). In our study FRAIL score $\geq 3$ was accepted frail and scores $<3$ non-frail. This study has been evaluated and approved by the İstanbul University faculty of medicine ethics committee on June 28, 2018 (Number: 956).

\section{Statistics}

Descriptive statistics were generated for all study variables. Kolmogorov-Smirnov test was used to determine normal or non-homegoneous distribution. All the numerical parameters revealed nonparametric with non-homogenous distribution. Numerical variables were given as median, mean and standard deviation and relative frequencies were given for categorical (qualitative) variables. The two independent groups were compared by Mann-Whitney $U$ test. Chi-square test with Yates's correction and Fisher's exact test was used for $2 \times 2$ contingency tables when appropriate for nonnumeric data. For further evaluation of the statistically significant data in univariate analysis, binary logistic regression analysis was used. $\mathrm{P}<0.05$ was accepted statistically significant. SPSS version 21
(IBM corporation, Armonk, NY, USA) was used for all statistical analysis in this study.

\section{Results}

Among a total of 1034 patients, 295 participants aged $\geq 60$ were included in this study (196 female and 99 male). Mean age was $75.6 \pm 6.8$ years. One hundred and forty-one patients (47.8\%) reported having insomnia. $28.3 \%$ of the patients had RLS and $39 \%$ of the patients reported at least one fall in the previous year. Prevalence of polypharmacy was found $82.7 \%$ and $16.7 \%$ of the patients were frail (Table 1). The relationship between insomnia and demographic data (gender and age), RLS, falls, frailty and polypharmacy are given in Table 2. There was no statistically significant difference between genders in terms of insomnia $(p=0.07)$. There was a borderline significant relation between age and insomnia $(p=0.05)$. There was no significant relationship between sleep and falls or frailty ( $p=0.26$ and 0.31 , respectively). The relations between insomnia and polypharmacy and insomnia and RLS were found statistically significant $(p=0.01)$. There was higher prevalence of RLS and lower prevalence of polypharmacy in patients with insomnia ( $p=0.01$ for both).

We performed regression analysis to find independent factors associated factors with insomnia. In regression analysis, the dependent variable was the presence of insomnia, independent variables were age, presence of RLS, falls and polypharmacy. Although we didn't find any relation between insomnia and falls in univariate analysis, we put it in regression analysis, as there are studies documenting independent relation between falls and insomnia in the older adults (18). A statistically significant relationship was found between insomnia and age, polypharmacy and RLS. Increased age, presence of polypharmacy and RLS were associated with higher rates of insomnia (Odd's ratios were 1.04, 1.83, 2.08, respectively) (Table 3)

Table 1. General demographic and geriatric syndrome data of the participants

\begin{tabular}{|l|l|}
\hline Male & $99(34 \%)$ \\
\hline Female & $196(66 \%)$ \\
\hline Age (years) & $75.6 \pm 6.8$ \\
\hline Insomnia & $141(47.8 \%)$ \\
\hline RLS & $83(28.3 \%)$ \\
\hline Falls & $115(39 \%)$ \\
\hline Polypharmacy & $244(82.7 \%)$ \\
\hline Frailty & $49(16.7 \%)$ \\
\hline
\end{tabular}

RLS: Restless leg syndrome; Data are given as number (\%) or mean \pm standard deviation as appropriate 


\begin{tabular}{|l|l|l|l|l|}
\hline \multicolumn{5}{|l|}{ Table 2. Univariate analyses for insomnia and related factors } \\
\hline Gender & Total & Insomnia (+) & Insomnia (-) & p \\
\hline Male $[\%,(n)]$ & $100 \%(99)$ & $41.4 \%(41)$ & $58.6 \%(58)$ & 0.07 \\
\hline Female [\%, (n)] & $100 \%(196)$ & $51 \%(100)$ & $49 \%(96)$ & 0.07 \\
\hline Age & $75.6 \pm 6.8$ & $76.3 \pm 7.0$ & $74.9 \pm 6.4$ & 0.05 \\
\hline RLS symptom (+) & $100 \%(85)$ & $58 \%(49)$ & $42 \%(36)$ & $0.01^{*}$ \\
\hline $\begin{array}{l}{[\%,(n)]} \\
\text { Fall in the previous year }\end{array}$ & $100 \%(112)$ & $50 \%(56)$ & $50 \%(56)$ & 0.3 \\
\hline $\begin{array}{l}{[\%,(n)]} \\
\text { Polypharmacy (+) }\end{array}$ & $100 \%(244)$ & $51.3 \%(125)$ & $48.7 \%(119)$ & $0.01^{*}$ \\
\hline $\begin{array}{l}{[\%,(n)]} \\
\text { Polypharmacy (-) }\end{array}$ & $100 \%(51)$ & $31.4 \%(16)$ & $68.6 \%(35)$ & $0.01^{*}$ \\
\hline Frailty & $100 \%(41)$ & $51.2 \%(21)$ & $48.8 \%(20)$ & 0.26 \\
\hline n: Number, ${ }^{*}$ Statistically significant, RLS: Restless leg syndrome & & & \\
\hline
\end{tabular}

Table 3. Logistic regression analysis for factors associated with insomnia

\begin{tabular}{|l|l|l|l|}
\hline Factor & $\begin{array}{l}\text { Odd's } \\
\text { ratio }\end{array}$ & $\begin{array}{l}\mathbf{9 5 \%} \\
\text { confidence } \\
\text { interval }\end{array}$ & $\mathbf{p}$ \\
\hline Age & 1.04 & $1.01-1.08$ & 0.029 \\
\hline Restless leg syndrome & 1.83 & $1.05-3.19$ & 0.033 \\
\hline Polypharmacy & 2.08 & $1.04-4.17$ & 0.038 \\
\hline $\begin{array}{l}\text { Dependent variable was the presence of insomnia; independent variables were age, } \\
\text { presence of restless leg syndrome, falls and polypharmacy }\end{array}$ \\
\hline
\end{tabular}

\section{Discussion}

Insomnia is a very prevalent problem in older age. In our study the prevalence of insomnia was found as $47.8 \%$. So far, the prevalence of insomnia in geriatric ages was reported between 18-65\% (8-11). Hence, our insomnia prevalence is in accordance with the literature documenting that nearly half of the older patients admitting to geriatric outpatient clinics have insomnia in Turkey.

We found the prevalence of RLS as $28.3 \%$ and presence of RLS was associated with the presence of insomnia $(p=0.01)$. RLS is defined as the unpleasant feeling that urges to move the limbs especially while resting and in the evening. RLS is highly prevalent among older adults and may contribute to difficulty in initiating and maintaining sleep (23). In a review the prevalence of RLS among older adults has been reported 9-20\% and mentioned as a good predictor for impaired sleep quality (23-24). In a study performed in Kayseri in Turkey, 665 cognitively intact older participants (aged $\geq 60$ years) were evaluated and the prevalence of RLS was estimated \%15.8 according to the criteria of International RLS group. RLS was significantly associated with impaired self-reported sleep quality and difficulty in falling asleep (25). Prevalence of RLS varies due to population characteristics and assessment method; either a single question or criteria. Our 28.3\% prevalence was similar to the previous studies. RLS was found to be associated with insomnia $(p=0.01)$ as expected. Therefore, we suggest that symptoms of RLS is better questioned as maybe a routine part of geriatric assessment. RLS may be a consequence of organic diseases (iron deficiency, neuropathy, renal failure) that are not uncommonly seen in the older adults and can lead to impairment in sleep quality.

In our study we didn't find a statistically significant a relationship between genders and insomnia $(p=0.07)$. Poorer subjective sleep quality in older women was reported in previous studies. In a meta-analysis a risk ratio of 1.41 for female versus male was found for the risk of insomnia (26). The gender effect was found stronger in the youngest population $(27,28)$. In a study Bonanni et al. (10) evaluated 1427 older patients and reported that while the prevalence of insomnia as a syndrome was higher in women than in men, it was not statistically significant. Also, there was found no significant different between both genders in a study conducted in Taiwan among 2045 noninstitutionalized older patients (29). In our study in older adults, insomnia was also more frequent in women (50.1\%) than men (41.4\%) but it did not reach statistical significance. So, our study also supports that the effect of gender on insomnia may decrease by ageing.

In our study, the relationship between age and insomnia was found borderline significant in univariate analysis and significant in the regression analysis. Our results are in line with the literature. Age is known as a risk factor for insomnia due to the multiple changes in sleep physiology. Older age was reported to be associated with higher frequency of insomnia. In a study, 2095 participants aged $\geq 18$ years (range: 18-100) were evaluated and a statistically strong association between age and insomnia ( $p=0.001)$ was detected (30). In another study, data were extracted from a wide group $(n=1423)$ of old participants (aged $\geq 60$ years, age was found to be related with worse sleep complaints. 
In our study, the prevalence of frailty was $16.7 \%$. Frailty is a common geriatric syndrome, particularly among older adults population and characterised with increased vulnerability to negative health outcomes, morbidity and mortality $(31,32)$. As sleep is an essential need for overall well-being, one could expect association between insomnia and frailty. In the literature some studies suggested association between frailty and insomnia (32), some did not (33). We did not find a significant association between frailty and insomnia. One could expect more severe problems related with sleep be more associated with frailty but we did not have severity grade for insomnia in this study. More studies are needed to state if there is a relation between frailty and insomnia.

We did not find a significant association between falls and insomnia but we found a significant relation between polypharmacy and insomnia. Falls are also common among older adults and a leading cause of morbidity and mortality. Falls have been thought to be related with sleep disturbances, as a consequence impaired attention and presence of sleepiness due to the effects of sleep disturbances (34). Also, the use of potentially inappropriate medications (i.e. benzodiazepines, antipsychotics, antidepressants) may be the cause of increased fall risk $(35,36)$. While some studies denoted independent relation between falls and insomnia $(18,36)$, more studies denoted that the relation between falls and insomnia revealed nonsignificant after adjustment with potential confounders $(18,37)$. As we found relation between polypharmacy and insomnia, maybe rather than the problems related to sleep, the use of inappropriate medications as hypnotics more related with the falls seen in subjects with insomnia.

Our patients had a high rate (82.7\%) of polypharmacy and the relation between insomnia and polypharmacy was significant. Different mechanisms are suggested to contribute to the relationship between polypharmacy and insomnia. Prevalence of chronic health conditions increases with age and the high number of comorbidities is a risk factor for polypharmacy. Some prevalent chronic diseases (e.g. diabetes mellitus, chronic heart failure, chronic renal disease, chronic pain) are related with the development of insomnia. So, polypharmacy may be the cause of insomnia indirectly due to the accompanying comorbidities. The number of medications can reflect underlying health problems as a consequence $(24,38)$. On the other hand, insomnia may be a side effect of medications. Some drugs are known to carry the risk of impairing sleep quality. Selective serotonin receptor inhibitors, selective serotonin noradrenaline reuptake inhibitors and tricyclic antidepressants can cause sleep disruption by suppressing Rapid eye movement (REM) sleep and increasing REM latency (39-41). Acetylcholine esterase inhibitors are reported as associated with sleep disturbances $(42,43)$. Alpha blockers, frequently prescribed to treat hypertension or prostatism may also impair sleep quality as they can trigger nightmares and day time sleepiness $(44,45)$ corticosteroids, beta-blockers, teophylline, diuretics, levodopa are the other possible drugs contributing to impaired sleep quality and insomnia in older patients (46-48). Also, the mechanism of polypharmacy in sleeping problems may also be a consequence of a cascade effect. Insomnia may be a side effect of a previously used medication and another drug may be prescribed to improve sleep $(24,49)$. To our knowledge, there is only one study looking for the relationship between polypharmacy and insomnia. In that recently published study, 379 participants aged between 78-102 were evaluated and no significant relation between insomnia polypharmacy was found after adjustment for potential confounders including the medical conditions (50). Our study suggested positive relation between polypharmacy and insomnia. However, we did not specify the type or number of chronic diseases or use of specific medications and adjust our results for them. The chronic diseases or medications themselves maybe the reason of association between polypharmacy and insomnia in our study.

\section{Study Limitations}

There are a number of limitations of this study. The sample size was not very large and the assessment for insomnia was performed with a single question. Also we didn't further analyses the concomitant illnesses and other possible related factors with insomnia (e.g. depression, anxiety disorder, chronic pain etc.) On the other hand, there are few studies evaluating the prevalence of insomnia and possible related factors among community-dwelling older persons in Eastern Europe. Polypharmacy is a highly prevalent medical burden with an increasing awareness and known many worse health outcomes. We found only one study evaluating the association between insomnia and polypharmacy. Our study stands as one of the few examples in this area.

\section{Conclusion}

In our study we found high prevalence of self-reported insomnia and RLS among older adults in Turkey as much as $47.8 \%$ and $39 \%$, respectively. Self-reported insomnia was associated with higher age, presence of RLS and polypharmacy. We suggest that insomnia and RLS maybe better questioned in routine health care of the older adults. Patients with higher age, polypharmacy and RLS seem to be at more risk to have insomnia and therefore shall be paid more attention.

\section{Ethics}

Ethics Committee Approval: This study has been evaluated and approved by the İstanbul University faculty of medicine ethics committee on June 28, 2018 (Number: 956). 
Informed Consent: Because of this study is a retrospective study, informed consent form was not taken.

\section{Peer-review: Internally and externally peer-reviewed.}

Financial Disclosure: The author declared that this study received no financial support.

\section{References}

1. Ryden A, Alessi C. Sleep disorders. In: Halter JB, Ouslander JG, Tinetti ME, Studenski S, High KP, Asthana S. Hazzard's Geriatric Medicine and Gerontology, 7th ed. New York, The McGrawHill Companies, 2016, pp 733.

2. Prerau MJ, Brown RE, Bianchi MT, Ellenbogen JM, Purdon PL. Sleep Neurophysiological Dynamics Through the Lens of Multitaper Spectral Analysis. Physiology (Bethesda) 2017;32:60-92.

3. Phillips B, Mannino D. Correlates of sleep complaints in adults: the ARIC study. J Clin Sleep Med 2005;1:277-283.

4. Zdanys KF, Steffens DC. Sleep Disturbances in the Elderly. Psychiatr Clin North Am 2015;38:723-741.

5. Sateia MJ, Buysse DJ, Krystal AD, Neubauer DN, Heald JL. Clinical Practice Guideline for the Pharmacologic Treatment of Chronic Insomnia in Adults: An American Academy of Sleep Medicine Clinical Practice Guideline. J Clin Sleep Med 2017;13:307-349.

6. Ellis JG, Perlis ML, Neale LF, Espie CA, Bastien CH. The natural history of insomnia: focus on prevalence and incidence of acute insomnia. J Psychiatr Res 2012;46:1278-1285.

7. Ohayon MM. Observation of the natural evolution of insomnia in the American general population cohort. Sleep Med Clin 2009;4:87-92.

8. Bloom HG, Ahmed I, Alessi CA, Ancoli-Israel S, Buysse DJ, Kryger MH, Phillips BA, Thorpy MJ, Vitiello MV, Zee PC. Evidence-based recommendations for the assessment and management of sleep disorders in older persons. J Am Geriatr Soc 2009;57:761-789.

9. Liang Y, Rausch C, Laflamme L, Möller J. Prevalence, trend and contributing factors of geriatric syndromes among older Swedes: results from the Stockholm County Council Public Health Surveys. BMC Geriatr 2018;18:322.

10. Bonanni E, Tognoni G, Maestri M, Salvati N, Fabbrini M, Borghetti D, Di Coscio E, Choub A, Sposito R, Pagni C, ludice A, Murri L. Sleep disturbances in elderly subjects: an epidemiological survey in an Italian district. Acta Neurol Scand 2010;122:389-397.

11. Voyer $P$, Verreault $R$, Mengue PN, Morin CM. Prevalence of insomnia and its associated factors in elderly long-term care residents. Arch Gerontol Geriatr 2006;42:1-20.

12. Tufan $A$, Ilhan $B$, Bahat $G$, Karan MA. An under-diagnosed geriatric syndrome: sleep disorders among older adults. Afr Health Sci 2017;17:436444.

13. Montplaisir J, Allen RP, Walters AS, Ferini-Strambi L. Restless legs syndrome and periodic limb movements during sleep. In: Kryger M, Roth T, Dement WC. Principles and Practice of Sleep Medicine, 4th ed. Saunders, New York, 2005, pp 839.

14. Cooper CB, Neufeld EV, Dolezal BA, Martin JL. Sleep deprivation and obesity in adults: a brief narrative review. BMJ Open Sport Exerc Med 2018;4:e00392.

15. Tobaldini E, Costantino G, Solbiati M, Cogliati C, Kara T, Nobili L, Montano N. Sleep, sleep deprivation, autonomic nervous system and cardiovascular diseases. Neurosci Biobehav Rev 2017;74:321-329.

16. Kreutzmann JC, Havekes R, Abel T, Meerlo P. Sleep deprivation and hippocampal vulnerability: changes in neuronal plasticity, neurogenesis and cognitive function. Neuroscience 2015;309:173-190.

17. Stone $K L$, Ensrud $K E$, Ancoli-Israel S. Sleep, insomnia and falls in elderly patients. Sleep Med 2008;9(Suppl 1):18-22.
18. Garfinkel D. Poly-de-prescribing to treat polypharmacy: efficacy and safety. Ther Adv Drug Saf 2018;9:25-43.

19. Roth T. Insomnia: definition, prevalence, etiology, and consequences. J Clin Sleep Med 2007;3(5 Suppl):7-10.

20. Ohayon MM, O'Hara R, Vitiello MV. Epidemiology of restless legs syndrome: a synthesis of the literature. Sleep Med Rev 2012;16:283-295.

21. Cadogan CA, Ryan C, Hughes CM. Appropriate Polypharmacy and Medicine Safety: When Many is not Too Many. Drug Saf 2016;39:109-116.

22. Morley JE, Malmstrom TK, Miller DK. A simple frailty questionnaire (FRAIL) predicts outcomes in middle aged African Ameris. J Nutr Health Aging 2012;16:601-608.

23. Celle S, Roche F, Kerleroux J, Thomas-Anterion C, Laurent B, Rouch I, Pichot V, Barthélémy JC, Sforza E. Prevalence and clinical correlates of restless legs syndrome in an elderly French population: the synapse study. J Gerontol A Biol Sci Med Sci 2010;65:167-173.

24. Miner B, Kryger MH. Sleep in the Aging Population. Sleep Med Clin 2017; 12:31-38.

25. Safak ED, Gocer S, Mucuk S, Ozturk A, Akin S, Arguvanli S, Mazicioglu $\mathrm{MM}$. The prevalence and related factors of restless leg syndrome in the community dwelling elderly; in Kayseri, Turkey: A cross-sectional study. Arch Gerontol Geriatr 2016;65:29-35.

26. Zhang B, Wing YK. Sex differences in insomnia: a meta-analysis. Sleep 2006;29:85-93.

27. Li RH, Wing YK, Ho SC, Fong SY. Gender differences in insomnia a study in the Hong Kong Chinese population. J Psychosom Res 2002;53:601-609.

28. Luca G, Haba Rubio J, Andries D, Tobback N, Vollenweider P, Waeber G, Marques Vidal P, Preisig M, Heinzer R, Tafti M. Age and gender variations of sleep in subjects without sleep disorders. Ann Med 2015;47:482-491.

29. Su TP, Huang SR, Chou P. Prevalence and risk factors of insomnia in community-dwelling Chinese elderly: a Taiwanese urban area survey. Aust N Z J Psychiatry 2004;38:706-713.

30. Ahmed AE, Al-Jahdali $H$, Fatani A, Al-Rouqi K, Al-Jahdali F, Al-Harbi A, Baharoon S, Ali YZ, Khan M, Rumayyan A. The effects of age and gender on the prevalence of insomnia in a sample of the Saudi population. Ethn Health 2017;22:285-294.

31. Fried $L P$, Tangen $C M$, Walston J, Newman $A B$, Hirsch $C$, Gottdiener J, Seeman T, Tracy R, Kop WJ, Burke G, McBurnie MA; Cardiovascular Health Study Collaborative Research Group. Frailty in older adults: evidence for a phenotype. J Gerontol A Biol Sci Med Sci 2001;56:146-156.

32. Graham JE, Snih SA, Berges IM, Ray LA, Markides KS, Ottenbacher KJ. Frailty and 10-year mortality in community-living Mexican American older adults. Gerontology 2009;55:644-651.

33. Vaz Fragoso CA, Gahbauer EA, Van Ness PH, Gill TM. Sleep-wake disturbances and frailty in community-living older persons. J Am Geriatr Soc 2009;57:2094-2100.

34. Chen TY, Lee S, Buxton OM. A Greater Extent of Insomnia Symptoms and Physician-Recommended Sleep Medication Use Predict Fall Risk in Community-Dwelling Older Adults. Sleep 2017:40.

35. Machado-Duque ME, Castaño-Montoya JP, Medina-Morales DA, CastroRodríguez A, González-Montoya A, Machado-Alba JE. Association between the use of benzodiazepines and opioids with the risk of falls and hip fractures in older adults. Int Psychogeriatr 2018;30:941-946.

36. Martinez-Ramirez D, Giugni JC, Almeida L, Walz R, Ahmed B, Chai FA, Rundle-Gonzalez V, Bona AR, Monari E, Wagle Shukla A, Hess CW, Hass $\mathrm{CJ}$, Okun MS. Association between antidepressants and falls in Parkinson's disease. J Neurol 2016;263:76-82.

37. Helbig AK, Döring A, Heier M, Emeny RT, Zimmermann AK, Autenrieth CS, Ladwig KH, Grill E, Meisinger C. Association between sleep disturbances and falls among the elderly: results from the German Cooperative Health Research in the Region of Augsburg-Age study. Sleep Med 2013;14:1356-1363. 
38. Sirois C, Laroche ML, Guénette L, Kröger E, Cooper D, Émond V. Polypharmacy in multimorbid older adults: protocol for a systematic review. Syst Rev 2017;6:104.

39. Molokhia M, Majeed A. Current and future perspectives on the management of polypharmacy. BMC Fam Pract 2017;18:70.

40. Wichniak A, Wierzbicka A, Jernajczyk W. Sleep and antidepressant treatment. Curr Pharm Des 2012;18:5802-5817.

41. Wilson S, Argyropoulos S. Antidepressants and sleep: a qualitative review of the literature. Drugs 2005;65:927-947.

42. Kazui $H$, Adachi $H$, Kanemoto $H$, Yoshiyama $K$, Wada T, Tokumasu Nomura K, Tanaka T, Ikeda M. Effects of donepezil on sleep disturbances in patients with dementia with Lewy bodies: An open-label study with actigraphy. Psychiatry Res 2017;251:312-318.

43. Boot BP. Comprehensive treatment of dementia with Lewy bodies. Alzheimers Res Ther 2015;7:45.

44. Roepke S, Danker-Hopfe H, Repantis D, Behnia B, Bernard F, Hansen ML, Otte C. Doxazosin, an $\alpha$-1-adrenergic-receptor Antagonist, for Nightmares in Patients with Posttraumatic Stress Disorder and/or Borderline Personality Disorder: a Chart Review. Pharmacopsychiatry 2017;50:26-31.
45. Kosari S, Naunton M. Sleep Disturbances and Nightmares in a Patient Treated with Prazosin. J Clin Sleep Med 2016;12:631-632.

46. Dokoohaki S, Ghareghani M, Ghanbari A, Farhadi N, Zibara K, Sadeghi H. Corticosteroid therapy exacerbates the reduction of melatonin in multiple sclerosis. Steroids 2017;128:32-36.

47. Scheer FA, Morris CJ, Garcia JI, Smales C, Kelly EE, Marks J, Malhotra A, Shea SA. Repeated melatonin supplementation improves sleep in hypertensive patients treated with beta-blockers: a randomized controlled trial. Sleep 2012;35:1395-1402.

48. Kamel NS, Gammack JK. Insomnia in the elderly: cause, approach, and treatment. Am J Med 2006;119:463-469.

49. Barczi SR, Teodorescu MC. Psychiatric and Medical Comorbidities and Effects of Medications in Older Adults. In: Kryger MH, Roth T, Dement WC. Principles and Practices of Sleep Medicine.6th ed. Philadelphia, PA: Elsevier, 2016.

50. Miner B, Gill TM, Yaggi HK, Redeker NS, Van Ness PH, Han L, Fragoso CAV. Insomnia in Community-Living Persons with Advanced Age. J Am Geriatr Soc 2018;66:1592-1597. 